Running head: Outbound Tourism from China

\title{
OUTBOUND TOURISM FROM CHINA: LITERATURE REVIEW AND RESEARCH AGENDA
}

\author{
Byron Keating $^{a^{*}}$, Anton Kriz \\ ${ }^{a}$ Centre for Business Services Science, University of Wollongong, Australia \\ ${ }^{\mathrm{b}}$ School of Business \& Management, University of Newcastle, Australia
}

Prepared: 1 August 2008

\section{*Corresponding author:}

Byron Keating, School of Information Systems and Technology, University of Wollongong, Northfields Ave, Wollongong, NSW 2522, Australia.

Tel: +61 24221 5315. Fax: +612 4221 4055. Email: bkeating@uow.edu.au.

\section{Acknowledgements:}

We thank Tim Coltman and Ali Quazi and two anonymous reviewers for their comments on earlier versions of the paper. We would also like to thank Sara Dolnicar and Greg Kerr for their feedback and contributions to the development of this paper. 


\title{
OUTBOUND TOURISM FROM CHINA: LITERATURE \\ REVIEW AND RESEARCH AGENDA
}

\begin{abstract}
The rapid growth of China's outbound tourism market has attracted a great deal of attention in recent years. However, the academic literature is still sparse in this area. Using a theoretical framework that synthesizes the key processes related to destination choice, the authors undertake a systematic review of the academic literature on outbound tourism from China. Stemming from this review, the paper provides some direction for future empirical research on this important topic. The authors also propose an episode model for travel planning, suggesting that traditional destination choice models may inadequately capture the nuances of destination choice in the Chinese context.
\end{abstract}

Keywords: China, outbound tourism, destination choice, research agenda. 


\section{INTRODUCTION}

The economic reforms introduced by Deng Xiao-Ping in 1978 were the building blocks for China's recent economic growth and, consequently, China's appreciation of tourism as an enabler for economic development and modernisation. In recent years, this growth has resulted in improvements in the standard of living for most Chinese and a commensurate increase in demand for international travel. From an international perspective, the projected growth of China's outbound tourism market has attracted a great deal of attention and has emerged as a very important export market for many Eastern and Western countries.

In the decade from 1994 to 2004, international tourism from China increased by 17\% per annum, resulting in a fourfold increase in the numbers of outbound international travelers (DFAT, 2005). While the absolute number of outbound Chinese tourists is impressive, the percentage of Chinese people travelling abroad relative to their population is small. With China's strong economic performance, there is a tremendous growth potential for Chinese outbound travel, especially by the expanding middle class in China. At its present rate of growth, China is expected to have 49 million tourists traveling abroad by 2008, growing to 100 million by 2015 (DFAT, 2005). China will have grown to become the fourth largest provider of outbound tourists globally by 2020 , representing $6.4 \%$ of all international tourism (WTO, 2005).

Given the significance of the Chinese outbound market, it is critical that tourism organizations develop informed strategies to capitalize on this opportunity. In particular, there has been a recent call for research that explores the buying behavior, traveling patterns, holiday preferences, and accommodation needs of the Chinese market (DITR, 2005). Presently, the academic literature in this area is sparse and provides little guidance on the decision-making processes of Chinese outbound tourists, or how best to service this market. A related challenge is to understand whether traditional destination choice models developed in a primarily Western context can be translated and applied to markets like China. 
The purpose of this paper is to summarize the current knowledge in the area of Chinese outbound tourism, and to provide some directions for future research in this area. To achieve this objective, the paper has been structured as follows. The next section begins by providing a theoretical framework to discuss our current understanding of destination choice. We then use this framework to guide a review of the academic literature relating to outbound tourism from China. Lastly, we provide an agenda for future research and discuss the implications of this work to academics and practitioners.

\section{THEORETICAL FRAMEWORK}

Destination choice has been a central issue in the study of tourism over the years (see, for example, Henshall et al., 1985; Woodside and Lyonski, 1989; Crompton, 1992), and remains an area of active research (Yuksel and Akgul, 2007; Correia et al., 2007; Nicolau and Mas, 2006). From an economic perspective, destination choice is concerned with issues of supply and demand, whereby tourism organizations package their various tourism products in ways that increase their relative competitiveness within a broader tourism market. While economists use prices to assess the value of goods and services, social theorists, particularly sociologists and consumer behaviorists, argue that price information does not reveal all forms of utility. Destination choice is influenced by an elaborate and complex combination of consumer needs and destination perceptions (Crompton, 1979).

A framework of pleasure travel destination choice was developed to provide a context for the current study (Figure 1). This framework identifies and integrates four sets of processes related to the impact of the key construct of destination image on destination choice. These processes consider: (1) the conceptualization of destination image; (2) the antecedents to destination image formation; (3) the impact of destination image on the selection of a specific travel destination; and (4) the influence of internal and external moderators.

\section{"Insert Figure 1 here"}

This framework synthesizes features of prior models of destination image and choice in tourism. Most notably, the proposed model integrates key concepts from the General Model of Traveler Leisure Destination Awareness and Choice (Woodside and Lysonski, 1989), the Pleasure Travel Destination Choice Model (Um and Crompton, 1990), and the Model for the 
Formation of Destination Image (Beerli and Martin, 2004a). These models collectively reflect our current understanding of destination selection for outbound tourists. The goal of the proposed framework is to provide a basis for considering the main issues that influence destination choice. The concepts used within the proposed framework are introduced in Table 1.

\section{"Insert Table 1 here"}

\section{Elaborating on the processes}

Destination image is acknowledged as a key driver of destination choice (Chon, 1992; Echtner and Ritchie, 1991; Stabler, 1988; Telisman-Kosuta, 1989). However, despite its importance, and despite three decades of scholarly attention, there is still no consensus on a definition of the construct, nor agreement on how it is formed (Gallarza et al., 2002; Ashworth and Voogt, 1990; Baloglu and Brinberg, 1997; Echtner and Ritchie, 1993). Part of this confusion, it is argued, has been the failure to adequately delineate the domain of the construct (Pike, 2002). In particular, many past investigations have conceptualized the construct in terms of poorly differentiated dimensions, which in many cases, would more appropriately be identified as antecedents to destination image (Correia et al., 2007).

For the purpose of this study, destination image is defined as the sum of beliefs, ideas, and impressions that a person has of a destination (Markin, 1974; Crompton, 1979; Embacher and Buttle, 1989). This definition encapsulates the domain of the construct and is consistent with other related definitions. The factors that drive the formation of a destination image in the minds of tourists are regarded as antecedents of the construct. These drivers have been previously referred to as the push/pull factors of tourism management (Dann, 1977; Crompton, 1979; Iso-Ahola, 1982; Uysal and Jurowski, 1993); and relate to the perceptions of the consumer as distinct from the characteristics of the destination.

The push factors are those attributes that predispose an individual to travel or to participate in a certain leisure activity. Previous research has tended to categorize these attributes into social and psychological groups. The social group relates to the socio-economic, cultural and demographic characteristics of the individual tourist, and the psychological group relates to his or her values, motivations and personality (Uysal and Hagan, 1993). This study has chosen to treat these two groups independently, recognizing that while the 
psychological factors play a critical role in the development of tourism consumption preferences, it is more useful to interpret the social factors in terms of their moderating influence. In particular, this delineation highlights the intuitive reality that socio-economic, cultural and demographic factors are more likely to limit access to opportunities than influence preferences and attitudes towards a destination. The key push attributes have been provided in Table 2.

\section{"Insert Table 2 here"}

Pull factors, on the other hand, reflect the attractiveness of a destination and relate to the specific bundle of attributes that represent the destination product. Beerli and Martin (2004a) assert that these attributes can be grouped under nine broad areas: natural attractions; general infrastructure; tourist infrastructure; leisure and recreation; art, history and culture; politics and economics; the environment; social issues; and atmospherics. The key pull attributes associated with each group have been provided in Table 3 .

\section{"Insert Table 3 here"}

The literature suggests that destination image, or attractiveness, is ultimately affected by the extent of congruence between the push and pull factors (Chon, 1992). Put more simply, people prefer to travel to destinations that have features that are aligned with their personal preferences. As such, a major strategic imperative for tourism organizations is to create product development and marketing strategies that are informed by, and aligned with, the expectations of prospective travelers from their key target markets. While this may seem logical, this carries an inherent challenge - to understand exactly how demand is affected by different degrees of alignment between these factors (Eymann and Ronning, 1997).

Accordingly, there is a need to understand how various internal and external factors influence the impact of the push/pull factors on destination image and/or its consequential impact on destination choice. Um and Crompton (1990) suggest that the social networks and political environment of travelers' home countries, and their exposure to marketing communications, are important external moderators that can influence the perceived attractiveness of a destination. The literature asserts that the extent of this impact is related to the level of normative influence exerted by social networks and political environments 
(Crompton, 1981) and the quality and relevance of the various marketing communications (Beerli and Martin, 2004a).

As indicated previously, the socio-economic, cultural, and demographic characteristics of tourists are also considered to have a significant influence on the perceptions of destination image and choice. For example, variables such as income, age, and education have been shown to influence the cognitive and affective assessment of a destination (Beerli and Martin, 2004b; Court and Lupton, 1997). However, Nicolau and Mas (2006) assert that more needs to be known about the impact of the cultural and psychographic differences on the interplay between consumer motivations, destination attributes, and destination choice. The key internal and external moderators are shown in Table 4.

"Insert Table 4 here"

\section{CHINESE OUTBOUND TOURISM}

Recent research on tourism development reports that outbound tourism in China began in the early 1980s and has progressed through three initial stages (Zhang and Heung, 2002). The first stage commenced in 1983, when the government allowed a limited number of organised tours to Hong Kong and, later, Macao. These tours were under the auspice of the China National Tourism Administration (CNTA) and were intended only for the purpose of visiting friends and relatives. The cost of this travel was required to be paid by the friends and relatives of the Chinese traveller.

The second stage began in 1990, when the government signed bilateral agreements with Singapore, Malaysia and Thailand. These agreements allowed Chinese leisure tourists to selffund travel to these countries through the newly established Chinese Travel Service.

However, the real birth of international tourism from China came about with the third stage. In 1997, the Chinese government signed its first bilateral agreements with the non-Asian countries of Australia and New Zealand, providing an opportunity for Chinese residents to experience Western culture firsthand.

Since that time, Chinese outbound tourism has been managed and regulated by the Approved Destination Status (ADS) system. This system is based on bilateral agreements between China and select overseas destinations. The ADS system restricts the overseas destinations to 
which Chinese nationals can travel, and restricts which foreign tour companies are allowed to operate in the Chinese market. By mid 2008, over 130 countries have been granted ADS by the CNTA, with the United States being the most recent country to join the ADS system (PRC, 2008).

The next sections of the paper will use the previously proposed framework (see Figure 1) to examine what we currently know about Chinese outbound tourism. Table 5 presents a chronological summary of the peer-reviewed literature relating to this topic. This table was compiled using a systematic review of the relevant literature. In particular, the review focused on key online databases and included all papers relating to outbound tourism from China. The systematic review also incorporated research dealing more generally with tourism development in China but excluded papers that focused on inbound issues or domestic tourism. These papers will provide the basis for a discussion of the key contextual issues influencing outbound tourism and destination choice from China.

\section{"Insert Table 5 here"}

\section{Push factors}

The most significant motivation for short-haul outbound Chinese travelers is acquiring new knowledge, followed by enhancing self-image, and, finally, building stronger relationships (Hanqin \& Lam, 1999). Their research identified that short-haul travelers to Hong Kong were most motivated by catching up with friends and relatives and experiencing something different. In particular, Zhou et al. (1998) assert that Chinese tourists are initially drawn to the most frequented attractions overseas, particularly to those which offer a marked contrast with what is found in China. Guo et al. (2007) suggests that this could be linked to a desire by the Chinese to escape the routine and drudgery of their everyday lives.

A key driver of long-haul travel by the Chinese is the attraction of visiting a capitalist society (Hsu and Lam, 2003). This finding is interesting as it contradicts the widely accepted truism that tourists prefer destinations that are culturally similar to their home country (Crouch, 1994). Unfortunately, there are no identified studies that examine the specific impacts of culture on destination choice by Chinese outbound travelers. The only related study in this area (Ng et al, 2007) reports that while cultural similarity was positively related to Australian 
tourists' choice of Asian destination, more research is required to better understand which specific dimensions of similarity (or difference) drive tourism intentions and consumption.

One possible explanation for this contradiction could be, as suggested by Boerjan (1995), that the amount of pre-trip planning required for long-haul travel can act to mitigate some of the psychological risk. To this end, Lo and Lam (2004) add that these risks could also be ameliorated by the values and experience of the traveler. For instance, prior research has found that more experienced travelers tend to be more adventurous and less likely to rely on structured travel. Thus, while such travelers would be more likely to encounter cultural differences and psychological risks, these are actually desirable characteristics for more adventurous travelers.

Another issue of significance for both long- and short-haul outbound travel relates to the dominance of group travel. Lo and Lam (2004) found that the vast majority of Chinese travelers still prefer the safety and convenience of packaged tours. In particular, they report that satisfaction for Chinese travelers is influenced by the expertise of the travel agent and the quality of information provided. However, Pan and Laws (2001) predict that the dominance of packaged travel is likely to decline as the Chinese outbound market matures.

\section{Pull factors}

Hanqin and Lam (1999) report that Chinese travelers to short-haul destinations desire a shopping paradise in a modern, cosmopolitan city, where the transportation systems and available services are of the highest standard. The importance of shopping is well supported in the literature (Hsu and Lam, 2003; Lehto et al., 2004), with some researchers suggesting that this could be linked to the Asian cultural value of building relationships through giftgiving (Mok and Iverson, 2000). Guo et al. (2007) also allude to the practice of network shopping, suggesting that the popularity of shopping is often linked to an obligation for Chinese tourists to shop for friends and relatives whilst overseas. To this end, they reveal that Chinese travelers report mixed feelings about their shopping experiences.

Sampling local food and sightseeing were also found to be important drivers for outbound Chinese travelers (Law et al., 2004). However, Guo et al (2007) reports that despite high expectations, the majority of Chinese travelers are not satisfied with their dining experiences 
overseas. Unfortunately, this research made no attempt to distinguish between short- and long-haul travel.

Specific to long-haul travel, Kim, Guo and Agrusa (2005) stress the importance of safety, beautiful scenery and well-equipped tourism facilities for Chinese tourists. Other destination attributes viewed as important include: shopping, dining, city sightseeing, visiting historical places, visiting amusement and theme parks, visiting national parks, and casinos/gambling (Cai et al., 2001). However, these studies made no attempt to ascertain how travelers' preferences for different destination attributes varied.

\section{Internal moderators}

Prior research reports that the influence of the various push and pull factors on short-haul destination choice is moderated by socio-economic factors (Hanquin and Lam, 1999). For instance, they report that motivation for building strong relationships is considered to be most important for female travelers and low-middle income earners. Conversely, males and higher income earners were found to be more interested in acquiring new knowledge. In terms of push factors, the most important driver was the desire for good service and facilities.

The results from a survey of travelers from the Republic of China (Taiwan) support these findings, adding that destination choice is moderated by gender and age (Lehto et al., 2004). In particular, they found that shopping-related short-haul vacations were more popular among younger females, whereas middle-aged men were more likely to undertake experiential travel.

One interestingly observation relates to a distinct lack of participation by older Chinese. Zhang et al. (2003) highlights that this is most likely related to a lack of suitable travel products that are designed to meet the specific needs of older Chinese travelers. This appears to be in stark contrast to their Western contemporaries, where the Baby Boomers (born postWorld War II) have a much higher relative wealth, and consequently, more active international travel habits.

In terms of long-haul travel, Cai et al. (2001) reveal that Chinese travelers are more likely to be middle class, middle-aged and of above average education than travelers to destinations closer to home. However, recent economic growth and more affordable air travel are opening 
up opportunities for China's younger educated professionals to travel abroad (Guo et al., 2007).

To this end, Hsu and Lam (2003) reveal that the most significant barriers to outbound travel to non-Asian destinations are the lack of adequate financial resources, difficulty in accessing travel services, and insufficient holiday time. These issues are particularly incumbent on the older Chinese working class and most likely influence the choice of a short- or long-haul destination.

Guo et al. (2007) contend that the cost of airline travel is still the single largest financial barrier to international travel for Chinese residents. They estimate that it represents $50-70 \%$ of the overall cost of outbound travel, representing the greatest barrier to long-haul travelers. However, Lo and Lam (2004) suggest that price sensitivity depreciates with the relative cost, distance, and uniqueness of the destination. Likewise, Lim and Wang (2008) identify the lack of universal leave entitlements as a key factor inhibiting travel by many Chinese. While leave entitlements are becoming more common for civil servants in the more affluent regions of China, this issue is likely to be a key issue for travel to long-haul destinations for some time to come.

Unfortunately, there appears to be a significant lack of research examining how these issues vary across different regions of China. Similarly, prior research has tended to ignore the interaction between specific traveler characteristics and their travel preferences.

\section{External moderators}

A key factor affecting Chinese outbound travel is the ADS system discussed previously. This system has two critical features. First, it limits the number of countries to which Chinese residents can easily travel. That is not to say that people cannot travel to other countries, but in such cases the process of obtaining a visa is considerably more complex and costly (Lim and Wang, 2008). Second, the ADS system also controls the negative impact of outbound travel on the Chinese economy by requiring that partner countries agree to a balance of payments in terms of arrivals and expenditures between the ADS destination and China. This can act to neutralize the economic incentive of pursuing Chinese outbound tourism.

Zhang et al. (2000) observe that the transition from a planned economy to a market economy has also strongly affected Chinese outbound travel. They suggest that as the transition 
progresses, the increased openness will lead to improved standards of service and reliability from China's tourism intermediaries. However, they caution that the progress could be slow, and the contrast between mature tourism markets and emerging markets such as China is likely to be the cause of some frustration.

From research conducted by Pan and Laws (2001), we see that the immaturity of the Chinese market is observed by their reliance on group travel. A particular structural challenge in the past was that this travel needed to be coordinated by a relatively small number of travel agents, and not all agents had the authority to arrange travel to all destinations. China's membership of the World Tourism Organization has resulted in further deregulation, culminating in 2005 with more open access by international travel intermediaries. This competition has contributed significantly to the growth in outbound travel and has been responsible for improved service standards and reliability.

These reforms have seen locally owned, small and medium travel enterprises respond well to the changing situation by partnering with foreign companies. Zhang and Morrison (2007) note that while the vast majority of Chinese travel intermediaries are small, family-owned enterprises lacking commercial acumen, they are learning quickly from their capitalist friends.

Zhang and Heung (2002) report that the attractiveness of outbound tourism is spreading beyond the Guangdong province to many of the smaller regions in China. However, they add that this change is not adequately reflected in the travel products are packaged or promoted by international destinations. Accordingly, they argue that there needs to be an appreciation by destinations that China is not one homogenous market. Further, while China is considered by international travel standards to be a relatively immature market, the extent of this immaturity is exaggerated as the tourism net is cast further afield. Zhang (2004) states that China's accession to the WTO has shortened the learning curve for tourists from outlying provinces.

However, destination countries serious about attracting a larger share of the Chinese market need to provide more flexible liberalize booking procedures as a matter of urgency, and undertake more visible and frequent promotions within China to improve travel industry and consumer awareness. To this end, Feng et al. (2004) assert that the gap between Western and Chinese destination marketing is well reflected in the design and features of their websites. 
They suggest that the sophistication of China's online marketing has paralleled the development of the outbound tourism industry, where the notion of the marketing concept is yet to generate sufficient traction to transform the industry from a product-centric to a service-centric industry.

Zhang et al. (2002) claim that these changes indicate that the tourism industry in China is in flux. They assert that as the Chinese government moves from control to coordination, the need for better communication within the industry is increasing. Further, they suggest that the industry needs to play a more active role in policy development. Cai et al. (2001) identified travel agencies as key players in this changing environment, as they are the main information source for leisure travelers, aside from informal sources, such as friends, relatives, and wordof-mouth.

\section{Destination image and choice}

Zhang et al. (2000) observe that the relative percentage of short-haul travel by Chinese residents is increasing relative to long-haul travel. While some of this shift can be explained in terms of economic transition, as previously mentioned, the recent flow of less experienced outbound travelers could point to trend where Chinese outbound travelers begin by visiting short-haul Asian destinations with a smaller cultural distance before building up to long-haul destinations as their experience matures.

This could also explain the lack of correlation between destination image and destination choice. For instance, Kim et al. (2005) declare that of the ADS-approved destinations, Australia is considered to be the most attractive by Chinese outbound tourists, followed by Singapore and Egypt. Interestingly, the uniqueness of Australia within the ADS subset may contribute to its attractiveness; the pair-wise comparisons between the ADS countries conducted by the authors found that Australia had no identifiable substitute in the minds of Chinese tourists. However, a positive destination image does not always correlate with destination choice. For instance, Lim and Wang (2008) reveal that despite Australia's popularity, it only ranks as the $10^{\text {th }}$ most popular destination in terms of actual travel. Of the non-Asian destinations, the most popular is Russia $\left(4^{\text {th }}\right)$, followed by the US $\left(7^{\text {th }}\right)$.

King et al. (2006) also raise the issue of non-ethical practices and their impact on destination image. Through the use of a case study of the Australia-China link, they discuss the impact of 
unethical shopping practices, false or misleading representation, and low service quality as key issues that have the potential to affect future tourism demand.

\section{ESTABLISHING A RESEARCH AGENDA}

From the preceding discussion, we can see that while there is much that we already know about the drivers of destination choice for Chinese outbound tourism, many issues still require investigation. From this review, we can clearly see the need for more research into the relative impact of culture as a critical variable in the choice of a destination. For instance, does cultural difference influence destination choice by Chinese travelers? If there is an influence, does this vary according to experience or some other factor? Table 6 provides a summary of the research questions that emerged from this review.

\section{"Insert Table 6 here"}

There is also a need to better understand how the relative importance of destination attributes varies for different groups of tourists. For instance, it is quite simple to compile from the literature a list of 20 or 30 pull factors that are perceived as attractive by Chinese tourists, yet we know little about how tourists trade-off between these factors when making a destination choice. Are certain destination features 'not-negotiable'? We need to better understand whether preferences vary systematically between different groups of travelers, and if so, how.

We also need to understand how changes in China's socio-political landscape will shape tourism policy now and in the future. For instance, what impact do changes in the ADS system and outbound tourism policy have on destination choice? Is it foreseeable that a time will come in the not too distant future when China's appetite for international travel will make it difficult to achieve a balance of payments for some of the existing ADS countries? Future research is needed to build on this paper by seeking to address questions such as these.

\section{Do we need a better model?}

At a more fundamental level, there is also the issue of whether the present ruling paradigm of destination choice (as depicted in Figure 1) is applicable to the study of Chinese outbound tourism. The traditional models of destination choice were developed in a mature, Western context, and it remains to be seen whether they apply in an immature, Eastern setting. These 
models postulate that destination choice consists of a common decision-making process, beginning with a consideration of destination attributes, the formation of a consideration set, the evaluation of constraints, and concluding with selection of a destination.

However, the process of destination choice can have several different points of origin. People do not always begin by deciding that they want to go on a vacation. The starting point may be the desire to engage in a certain activity; the desire to visit family; the desire to spend romantic time with a loved one; or even the desire to experience the unique attributes of a certain destination.

The notion that destination or itinerary selection may occur before making the decision to travel is diametrically opposed to the current understanding of destination choice. An alternative destination choice paradigm could be particularly relevant to the study of destination choice in China because of the ADS system and imposed limitations on the range of destinations and travel options available. Situational factors such as shorter holiday periods and the high cost of long-haul travel could also be utilized to explain different travel episodes. Key to the detection of the most common travel episodes in China is an understanding of the key moderator variables. As such, the episode model centralizes the moderators to show how internal and external factors can be applied in order to explain and capture an individual's travel preferences.

\section{CONCLUSION}

From the preceding discussion, we can see that this paper has made a significant contribution to our understanding of destination image and choice for outbound Chinese travelers. The research achieved this objective by positing a theoretical framework for pleasure travel and then using this framework to explore the main issues affecting destination selection in China.

Key insights from this research should inform future investigations of destination choice in China, providing a foundation for a better understanding of the complexities of destination choice within a non-Western setting. As the outbound tourism market from China is still developing, the choices and opportunities for travelers have been limited. Yet with increasing incomes and relaxing government restrictions, the challenge for future research will be to understand the key triggers of Chinese tourism decision-making and consumption behaviour. 
The theoretical framework introduced in this paper provides a valuable tool for exploring the various factors that drive and influence destination decisions. It represents an extension to previous models of destination choice and destination image, integrating key aspects from these two complimentary areas of study within tourism. As demonstrated through the ensuing discussion, the framework served as a useful tool for interpreting how destination images are formed and how choices are made. However, we recognize that there are a number of areas that require further investigation.

Future research should empirically build on this paper. In particular, attention could be given to resolving the identified research issues. While a key limitation of this paper is that it focuses solely on the academic literature, future research could supplement the findings of this research with a review of industry literature. Perhaps some of the questions raised have already been answered. We also recognize that in using a framework (particularly one developed in a Western context) to review the literature, we may not have considered all destination choice issues in China. In this regard, we suggest that a new model of travel planning could be of some value. However, we caution that any subsequent work in this area needs to employ methods that are culturally appropriate for investigating these issues within the Chinese context.

Beyond theory, tourism marketing managers and operators may find this paper to be of value for crafting better, more informed product development and marketing strategies. In particular, tourism practitioners should be able to create strategies that are informed by a greater understanding of the internal and external moderators that influence the impact of the various push and pull attributes on destination image and choice. 


\section{REFERENCES}

Ashworth, G. \& Voogt, H. (1990). Selling the City. London: Belhaven.

Baloglu, S. \& Brinberg, D. (1997). Affective images of tourism destinations, Journal of Travel Research, 35(4), 11-15.

Baloglu, S. \& McCleary, K. (1999). A model of destination image formation, Annals of Tourism Research, 26(4), 868-897.

Beerli, A. \& Martin, J. (2004a). Factors influencing destination image, Annals of Tourism Research, 31(3), 657-681.

Beerli, A. \& Martin, J. (2004b). Tourists' characteristics and the perceived image of tourist destinations: a quantitative analysis--a case study of Lanzarote, Spain, Tourism Management, 25(5), 623-636.

Boerjan, P. (1995). Do we need a distinction between short and long holidays?, The Tourist Review, 33, 11-17.

Cai, Lehto \& O’Leary (2001)

Chon, K. (1992). Self-image/destination image congruity, Annals of Tourism Research, 19(2), 360-363.

Cohen, E (1972). Toward a Sociology of International Tourism, Social Research, 39(1), 164182.

Correia, A., do Valle, P. \& Moço, C. (2007). Why people travel to exotic places, International Journal of Culture, Tourism and Hospitality, 1(1), 45-61.

Court, B. \& Lupton, R. (1997). Customer Portfolio Development: Modeling Destination Adopters, Inactives, and Rejecters, Journal of Travel Research, 36(1), 35-43.

Crompton, J. (1992). Structure of vacation destination choice sets, Annals of Tourism Research, 19(3): 420-434.

Crompton, J. (1979). Motivations for pleasure vacation, Annals of Tourism Research, 6(4), 408-424.

Crompton, J. (1981). Dimensions of the social group role in pleasure vacations, Annals of Tourism Research, 8(4), 550-568.

Crouch, G. (1994). Demand elasticities for short-haul versus long-haul tourism, Journal of Travel Research, 34, 2-7.

Dann, G. (1977). Anomie, ego-enhancement and tourism, Annals of Tourism Research, 4(4), 184-194.

DFAT (2005). Unlocking China's Service Sector. Canberra, Australian Government: Department of Foreign Affairs and Trade.

DITR (2005). National Tourism Emerging Markets Strategy: China and India. Canberra, Australian Government: Department of Industry, Tourism and Resources. 
Echtner, C. \& Ritchie, J. (1991). The Meaning and Measurement of Destination Image, Journal of Tourism Studies, 2(2), 2-12.

Echtner, C. \& Ritchie, J. (1993). The Measurement of Destination Image: An Empirical Assessment, Journal of Travel Research, 31(4), 3-13.

Embacher, J. \& Buttle, F. (1989). A Repertory Grid Analysis Of Austria's Image As A Summer Vacation Destination, Journal of Travel Research, 27(3), 3-7.

Eymann, A. \& Ronning, G. (1997). Microeconometric models of tourists' destination choice, Regional Science and Urban Economics, 27(6), 735-761.

Feng, R., Morrison, A. \& Ismail, J. (2004). East versus west: A comparison of online destination marketing in China and the USA, Journal of Vacation Marketing, 10(1), 4356.

Gallarza, M. Saura, I. \& Garcia, H. (2002). Destination image: Towards a Conceptual Framework, Annals of Tourism Research, 29(1), 56-78.

Guo, Y., Kim, S. \& Timothy, D. (2007). Development characteristics and Implications of mainland Chinese outbound tourism, Asia Pacific Journal of Tourism Research, 12(4), 313-332.

Hanqin, Z. \& Lam, T. (1999). An analysis of Mainland Chinese visitors' motivations to visit Hong Kong, Tourism Management, 20(5), 587-594.

Henshall, B., Roberts, R. \& Leighton, A. (1985). Fly-Drive Tourists: Motivation and Destination Choice Factors, Journal of Travel Research, 23(3), 23-27.

Hofstede, G. (2005). Cultures and Organizations: software of the mind, New York: McGrawHill.

Hsu, C. \& Lam, T. (2003). Mainland Chinese travelers' motivations and barriers of visiting Hong Kong, Journal of the Academy of Business and Economics, 11(1), 60-67.

Iso-Ahola, S. (1982). Toward a social psychological theory of tourism motivation: A rejoinder, Annals of Tourism Research, 9(2), 256-562.

Kim, S., Guo, Y. \& Agrusa, J. (2005). Preference and position analyses of overseas destinations by mainland Chinese outbound pleasure tourists, Journal of Travel Research, 44, 212-220.

King, B., Dwyer, L. \& Prideaux, B. (2006). An evaluation of unethical business practices in Australia's China inbound tourism market, International Journal of Tourism Research, 8, 127-142.

Law, R., Cheung, C. \& Lo, A. (2004). The relevance of profiling travel activities for improving destination marketing strategies, International Journal of Contemporary Hospitality Management, 16(6), 355-362.

Lehto, X., Cai, L., O’Leary, J. \& Huan, T. (2004). Tourist shopping preferences and expenditure behaviours: The case of the Taiwanese outbound market, Journal of Vacation Marketing, 10(4), 320-332. 
Li, L. \& Buhalis, D. (2006). E-Commerce in China: The case of travel, International Journal of Information Management, 26, 153-166.

Lim, C. \& Wang, Y. (2008). China's post-1978 experience in outbound tourism, Mathematics and Computers in Simulation, 78, 450-458

Lo, A. \& Lam, T. (2004). Long-haul and short-haul outbound all-inclusive package tours, Asia Pacific Journal of Tourism Research, 9(2), 161-176.

Markin, R. (1974). Consumer Behavior: A Cognitive Orientation, New York: Macmillan.

Mok,C. \& Iverson, T. (2000). Expenditure based segmentation: Taiwanese tourists to Guam, Tourism Management, 21(3), 299-305.

Moutinho, L., Huarng, K., Yu, T. \& Chen, C. (2008). Modeling and forecasting tourism demand: the case of flows from mainland China to Taiwan, Service Business, 2, 219-232.

Ng, S., Lee, J. \& Soutar, G. (2007). Tourists' intention to visit a country: The impact of cultural distance, Tourism Management, 28(6), 1497-1506.

Nicolau, J. \& Mas, F. (2006). The influence of distance and prices on the choice of tourist destinations: The moderating role of motivations, Tourism Management, 27(5), 982-996.

Pan, B. \& Laws, E. (2001). Tourism marketing opportunities for Australia in China, Journal of Vacation Marketing, 8(1), 39-48.

Pike, S. (2002). Destination image analysis--a review of 142 papers from 1973 to 2000, Tourism Management, 23(5), 541-549.

Plog, S. (1987). Understanding psychographics in tourism research, Travel, Tourism and Hospitality Research: A Handbook for Managers and Researchers, 203-213.

Prideaux, B. (1996). Recent developments in the Taiwanese tourist industry - implications for Australia, International Journal of Contemporary Hospitality Management, 8(1), 10-15.

PRC (2008). 1st organized group travel to U.S. starts. http://www.gov.cn/misc/200806/18/content_1019777.htm, Accessed 30 June 2008.

Stabler, M. (1988). The image of destination regions: theoretical and empirical aspects. In Goodall, B. \& Ashworth, G. (Eds.), Marketing in the tourism industry: the promotion of destination regions (pp. 133-61), London: Groom Helm Publishing.

Telisman-Kosuta, N. (1989). Tourist destination image. In S. Will \& L. Moutinho (Eds.), Tourism marketing and management handbook (pp. 555-61), Cambridge: Prentice Hall.

Um, S. \& Crompton, J. (1990). Attitude determinants in tourism destination choice, Annals of Tourism Research, 17(3), 432-448.

Uysal, M. \& Jurowski, C. (1993). An Empirical Testing of the Push and Pull Factors of Tourism Motivations, Annals of Tourism Research, 21(4), 844-846.

Uysal, M. \& L. Hagan (1993). Motivation of pleasure travel and tourism. In Khan, M., Olsen, M. \& Var, T. (Eds.), Encyclopedia of Hospitality and Tourism (pp. 798-810), New York: Van Nostrand Reinhold. 
Woodside, A. \& Lysonski, S. (1989). A General Model Of Traveler Destination Choice, Journal of Travel Research, 27(4), 8-14.

WTO (2005). Asian Destinations on the Rise in World Tourism Rankings. http://www.worldtourism.org/newsroom/Releases/2005/May/asian.htm, Accessed 14 May 2007.

Xiao, H. (2006). The discourse of power: Deng Xiaoping and tourism development in China, Tourism Management, 27, 803-814.

Yuksel, A. \& Akgul, O. (2007). Postcards as affective image makers: An idle agent in destination marketing, Tourism Management, 28(3), 714-725.

Zhang, H., Li, X. \& Qin, Y. (2003). On the present situation and trend of China outbound tourism, Commercial Research, 2003(2), 147-152.

Zhang, H. (2004). The challenges and opportunities facing travel service industry upon China's accession to world trade organization, International Journal of Contemporary Hospitality Management, 16(6), 369-372.

Zhang, H., Chong, K. \& Jenkins, C. (2002). Tourism policy implementation in mainland China: An enterprise perspective, International Journal of Contemporary Hospitality Management, 14(1), 38-42.

Zhang, H. \& Heung, V. (2002). The emergence of the mainland Chinese outbound travel market and its implications for tourism marketing, Journal of Vacation Marketing, 8(1), 7-12.

Zhang, H. \& Morrison, A. (2007). How can the small to medium

sized travel agents stay competitive in China's travel service sector?, International Journal of Contemporary Hospitality Management, 19(4), 275-285.

Zhang, G., Pine, R. \& Zhang, H. (2000). China's international tourism development: The present and future, International Journal of Contemporary Hospitality Management, 12(5), 282-290.

Zhang, H. \& Qu, H. (1996). The trends of China outbound travel to Hong Kong and its implications, Journal of Vacation Marketing, 2(4), 373-381.

Zhou, L., King, B. \& Turner, L. (1998). The China outbound market: An evaluation of key constraints and opportunities, Journal of Vacation Marketing, 4, 120-135. 
Figure 1: Theoretical framework for destination choice

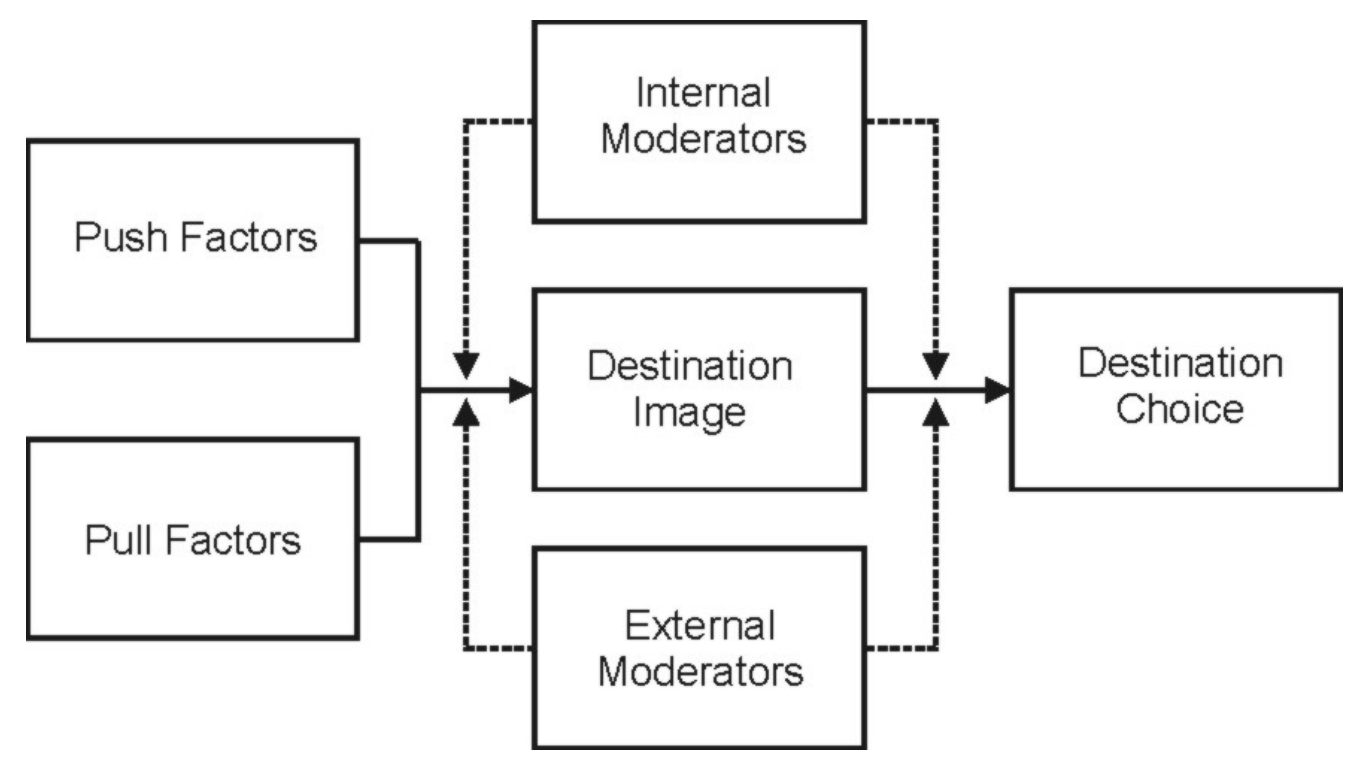


Table 1: Description of concepts

\begin{tabular}{ll}
\hline Concepts & Description \\
\hline Push Factors & $\begin{array}{l}\text { Considered to be the dominant set of attributes that can be used to describe } \\
\text { the different generic motivations for tourism consumption. These are } \\
\text { individual-specific and include factors such as values, motivations and } \\
\text { personality. }\end{array}$ \\
& $\begin{array}{l}\text { Considered to be the dominant set of attributes that can be used to describe } \\
\text { the various types of generic destination products available in the tourism } \\
\text { system. These are destination-specific and include factors such as natural } \\
\text { resources, tourism infrastructure, art, and history. }\end{array}$ \\
Internal Moderators & $\begin{array}{l}\text { Considered to be the specific internal drivers that influence perceptions of } \\
\text { destination image and the actual decision to visit a particular destination. }\end{array}$ \\
Comprised of socio-economic, cultural, and demographic characteristics of \\
individual tourists.
\end{tabular}




\section{Table 2: Push attributes}

\begin{tabular}{ll} 
Groups & Attributes \\
\hline Values & $\begin{array}{l}\text { Venturesome, pleasure-seeker, impassive, self-confident, planners, } \\
\text { masculine, intellectual and people-oriented. }\end{array}$ \\
Motivation & Organized mass tourist, individual mass tourist, explorer, drifter. \\
Personality & Allocentric and psychocentric.
\end{tabular}

Source: Baloglu \& McCleary, 1999; Uysal \& Hagan, 1993; Plog, 1987; Cohen, 1972; Hofstede, 2005. 
Table 3: Pull attributes

\begin{tabular}{|c|c|}
\hline Groups & Attributes \\
\hline Natural resources & Weather, beaches, countryside, variety of flora and fauna. \\
\hline General infrastructure & $\begin{array}{l}\text { Roads, airports, ports, private/public transport, health services, } \\
\text { telecommunications, commercial infrastructure and building } \\
\text { development. }\end{array}$ \\
\hline Tourist infrastructure & $\begin{array}{l}\text { Hotel accommodation, restaurants, bars, nightlife, easy access, } \\
\text { excursions, tourist information/services. }\end{array}$ \\
\hline Leisure and recreation & Theme parks, sports and entertainment activities, casinos. \\
\hline $\begin{array}{l}\text { Art, history and } \\
\text { culture }\end{array}$ & Museums, festivals, craft, gastronomy, folklore, religion and customs. \\
\hline Political and economic & Stability, economic development, safety, affordability. \\
\hline Environment & Scenery, cleanliness, low pollution, low congestion. \\
\hline Social & Friendliness of locals, visible poverty, quality of life, language barriers. \\
\hline Atmosphere & $\begin{array}{l}\text { Luxurious, fashionable, exclusive, family oriented, exotic, mystic, } \\
\text { relaxing, fun and interesting. }\end{array}$ \\
\hline
\end{tabular}

Source: Beerli \& Martin, 2004a. 
Table 4: Internal and external moderators

\begin{tabular}{ll}
\hline Groups & Attributes \\
\hline Internal moderators & $\begin{array}{l}\text { Age, gender, income, education, marital status, family life-cycle, family } \\
\text { size, culture, race/ethnic group, occupation, home ownership. }\end{array}$ \\
External moderators & $\begin{array}{l}\text { Past experiences (signicative), advertising and marketing communication } \\
\text { (symbolic) and information from friends and family (social). }\end{array}$ \\
\hline
\end{tabular}

Source: Baloglu \& McCleary, 1999; Um \& Crompton, 1990; Uysal \& Hagan, 1993. 
Table 5: Review of key literature

\begin{tabular}{ll}
\hline Research & Major Finding \\
\hline Prideaux (1996) & $\begin{array}{l}\text { Summarizes the growth in tourism from the Republic of China (Taiwan) and } \\
\text { examines a range of issues affecting growth. Issues addressed include } \\
\text { promotion, language training, culinary requirements and air services. }\end{array}$ \\
Zhang \& Qu (1996) & $\begin{array}{l}\text { Attempts to provide a better understanding of mainland Chinese outbound } \\
\text { travel to short-haul destinations. China's economic boom and the political } \\
\text { relaxation allowing its citizens to go to neighboring countries are considered } \\
\text { to be the main cause. }\end{array}$ \\
Zhou, King \& & $\begin{array}{l}\text { Chinese tourists are drawn initially to the most frequented attractions } \\
\text { overseas, and particularly to those which offer a marked contrast with what is } \\
\text { found in China. The intrinsic attributes of the attractions are found to be of } \\
\text { secondary importance. It is suggested that destination countries serious about } \\
\text { the Chinese market need to liberalise booking procedures as a matter of } \\
\text { urgency. Greater promotion by destination countries is needed within China } \\
\text { to improve travel industry and consumer awareness. }\end{array}$
\end{tabular}

Hanqin \& Lam (1999)

The importance of the China outbound market has drawn scholars' interests in understanding what motivates Mainland Chinese to travel overseas. A model based on push and pull factors is developed as a conceptual framework for the study, and the results indicate that the importance of push and pull factors in motivating Chinese travelers can be different from that found in other studies. The study also suggests that there is a significant relationship between travel motivations and social demographic factors.

Zhang, Pine and Zhang (2000)

The growth of international tourism from China has become an important economic issue. The paper explains the main stages of its development and identifies the important changes in the past two decades. It analyzes the opportunities and challenges with which China's international tourism is confronted, and further suggests the choices of policies and strategies China should undertake for its international tourism development in the new millennium.

Pan \& Laws (2001) Provides analysis of the growing demand for outbound tourism from China and describes the special characteristics of the market. It analyses the significance of guanxi, and the opportunities for long-haul tour operators to improve the service they provide to visiting Chinese groups.

Cai, Lehto \&

O’Leary (2001)

Zhang \& Heung (2002)
This study profiled the characteristics of US bound Chinese travelers in terms of their age, gender, income, occupation, lead time of pre-trip preparation, information sources, duration of stay, expenditure patterns, package usage, and participation rates of activities.

Analyses the current trends in the mainland Chinese outbound travel to shorthaul destinations such as Hong Kong. The study considers trends in performance and the main social, economic and political factors affecting the emergence of the China outbound market. Also focuses on the policy implications for the tourism industry in the region. 
Zhang, Chong \& Jenkins (2002)

Lehto, Cai, O'Leary \& Huan (2004)

Law, Cheung \& Lo (2004)

Zhang (2004)

Lo \& Lam (2004)

Feng, Morrison \& Ismail (2004)

Kim, Guo \& Agrusa (2005)

King, Dwyer \& Prideaux (2006)
Examines tourism policy implementation in Chinese tourism enterprises. Chinese tourism policies were found to have established a legal framework for the administration, management and operation of tourism enterprises. However, some regulations are viewed as too strict, limiting the opportunity for tourism enterprises to react to market changes. The study provides important implications for studying the political dimension of tourism in the context of socialist countries.

Identifies the importance of shopping as a driver of destination choice in Chinese outbound travel. Results indicate that travel purpose, travel style, age and gender were significant factors influencing shopping preferences and destination choice. Suggestions were made regarding destination marketing, product development, retail merchandising and customer service.

This paper examines the perception of travel activities for tourists from the Hong Kong Special Administrative Region of China. Results indicate that travelers perceive visiting friends/relatives and dining as the most important activities, whereas outdoor sports was perceived as the least important activity. Also discusses the destination marketing issues.

Discusses China's accession to World Tourism Organization, and the impact of open market competition in China. Through studying and investigating the developing history and the current operating condition of the travel agents, this paper analyses opportunities and challenges facing China's travel agents and their impact of outbound travel.

Considers the criteria used by Chinese travelers for the selection of package tours. This study identifies the main criteria, and the differences between long and short-haul travelers. The results show that personal safety and the guarantee of a promised departure date were the most important criteria.

Explores the use of online marketing between the USA and China. By applying a modified balanced scorecard approach, website marketing strategies, web page designs, marketing information and technical qualities were evaluated.

Examined the competitiveness of overseas destination countries where potential Mainland Chinese outbound tourists consider making an overseas travel. Mainland Chinese respondents considered "safety" and "beautiful scenery" to be the most important attributes.

This paper examined the prevalence of unethical practices within the Chinese tourism sector. The range and nature of the practices are outlined in the context of the structure of outbound operations in China and inbound operations in Australia. The impact of the practices on the growth of the market is evaluated, as are the negative impacts on destination image.

The article investigates the online marketing features most influencing travelers in China. Age, area of residence, type of travel website most visited, length of time using the Internet, self efficacy, domain-specific innovativeness and perception of the Internet all impact on Chinese lookers becoming bookers. 
Xiao (2006)

Guo, Kim \&

Timothy (2007)

Zhang \& Morrison (2007)

Lim \& Wang (2008) Chinese outbound tourism has been managed and regulated by the Approved Destination Status (ADS) system, which is based on bilateral tourism agreement between China and overseas destinations. This paper uses time series modeling to analyze Chinese tourist travel patterns to a long-haul destination (Australia).

Moutinho, Huarng, Yu \& Chen (2008)

This article discusses China's tourism development and policy through a discourse analysis of Deng Xiaoping's talks on tourism. The analysis offers a perspective on tourism development and policy in a developing and/or socialist country.

This paper provides a thorough examination of the Mainland Chinese demand for outbound travel. It analyses the impacts of the Mainland Chinese outbound tourism market according to factors such as policy, economy and socio-political issues. The origins, destination perceptions and organization of Mainland Chinese outbound tourists are also explained, together with the negative impacts of tourism on Mainland Chinese travelers.

This research explores the role of SME travel agents in China. The findings indicate that being small in size and simple structure, short period of time in business operation, lack of management experience and market recognition are major impediments to their competitiveness.

This paper identifies and forecasts Mainland Chinese demand for travel to short-haul destinations based on a set of parsimonious variables and neural networks.

Source databases: ABI Inform (Proquest), Business Source Premier (EBSCO), Expanded Academic (Gale), Informaworld, ScienceDirect, Springerlink, Emerald Fulltext, Wiley Interscience. 
Table 6: What we still don't know

\begin{tabular}{|c|c|}
\hline Concepts & Research questions \\
\hline Push Factors & $\begin{array}{l}\text { - How do travel motivations for short- and long-haul tourist markets in } \\
\text { China differ? } \\
\text { - To what extent are our views of tourism processed via a Western filter? } \\
\text { - Can we classify Chinese tourists according to established typologies } \\
\text { for values, motivation and personality? }\end{array}$ \\
\hline Pull Factors & $\begin{array}{l}\text { - Do Chinese differ in their preference for different destination } \\
\text { attributes? } \\
\text { - What particular infrastructure requirements do Chinese outbound } \\
\text { tourists value? } \\
\text { - To what extent do social issues such as language and service quality } \\
\text { moderate the attractiveness of a destination? }\end{array}$ \\
\hline Internal Moderators & $\begin{array}{l}\text { Do family-related attributes (i.e., life-cycle, size and composition) } \\
\text { affect destination choice? } \\
\text { - How do education levels affect destination perceptions and travel } \\
\text { decisions? } \\
\text { - How do cultural issues (i.e., distance, individualism and masculinity) } \\
\text { affect destination choice? } \\
\text { - Does the impact of culture depreciate with market maturity and/or } \\
\text { experience? }\end{array}$ \\
\hline External Moderators & $\begin{array}{l}\text { What aspects of marketing influence travel planning and destination } \\
\text { choice? } \\
\text { - How do socio-political factors influence travel decisions? } \\
\text { - How can the early ADS countries preserve market share as more } \\
\text { countries are added to the list? } \\
\text { How can the Chinese travel industry play a larger role in the } \\
\text { development of tourism policy? }\end{array}$ \\
\hline $\begin{array}{l}\text { Destination image and } \\
\text { choice }\end{array}$ & $\begin{array}{l}\text { - How do past travel experiences moderate destination image } \\
\text { perceptions? } \\
\text { - How can destinations with similar pull factors differentiate themselves } \\
\text { within China? } \\
\text { - Can we rely on traditional models and research methods to measure } \\
\text { travel perceptions in China? }\end{array}$ \\
\hline
\end{tabular}

